\title{
THE EFFECT OF BITCOIN ON THE GLOBAL ECONOMY IN THE CONTEXT OF THE EVOLUTION OF CONCEPTS RELATED TO DIGITAL DEVELOPMENT
}

\author{
Bilal Jibai \\ Ahmad Nassour \\ Notre Dame University - Louaize, Beirut, Lebanon
}

This study intends to sort out what will be the normal choices of the customary financial frameworks and how the world economy will draw in and manage those normal other options. Since technological improvement is profoundly quick and momentous, it is imperative to comprehend the discernments, practices, correspondence, and the possibility of selection of those other options. Advanced monetary standards and cryptographic forms of money are non-customary financial monetary forms that depend on something referred to as blockchain innovation. There are an excessive number of advanced digital forms of money these days, all of them having their own attributes and specificities. A portion of those advanced digital currencies will be studied in this research. It is imperative to mention here that only one out of every odd nation acknowledges the progress in this area, and such nations arrangement are often influenced by their World Bank rank - low, lower-middle, upper-middle, and high-income countries. More, this research looks at the social side of bitcoin and blockchain development in these nations. Bitcoin is tremendously influencing the economy overall. That's why it quickly became of interest for many financially trained professionals and academicians. Unfortunately, this type of money has been increasingly used for criminal activities too. This research discusses all these sides as well as the important impacts bitcoin has on the population.

Keywords: bitcoin, investment, financial market, pandemic

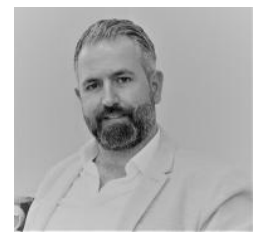

\section{Bilal Jibai}

Ph.D., Assistant Professor

Department of Management \& Marketing, Faculty of Business Administration and Economics, Notre Dame University, Beirut, Lebanon

Research interests: financial market, banking, bank marketing, customer behavior Email: bjibai@ndu.edu.lb

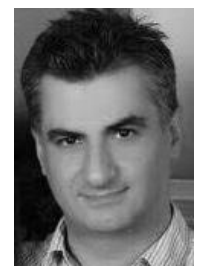
Ahmad Nassour
MBA student, Lebanese International University, Lebanon Research interests: finance, digitalization, digital money
Email: 11910061@students.liu.edu.lb 


\section{THE EFFECT OF BITCOIN ON THE GLOBAL ECONOMY}

\section{Introduction}

As the world turns out to be progressively digital, digital currency is the next characteristic advance in the development of cash. Currently, our regular monetary exchanges depend upon a confided third party to keep a record of exchanges (Mendoza et al, 2018). For instance, when you do a bank exchange, its financial framework keeps a record and ensures that the exchange is protected. Example: when Tracy moves $\$ 10$ to Patrick utilizing PayPal, PayPal keeps a focal record of $\$ 10$ charged from Tracy's record and $\$ 10$ credited to Patrick's account. Delegates like banks, PayPal, and various other players from the current monetary framework play a significant part in directing the world's monetary exchanges (Larios-Hernandez, 2017).

Bitcoin cryptocurrency was designed to be the first decentralized type of digital cash, thus removing the need for conventional financial intermediaries such as banks and governments. At first, it was rejected and it was treated as laughable in the opinion of many people. Whilst, some people were also convinced that it was a truly global currency. Today you might find those passionate people behind bitcoin all over the world (Maurer et al., 2013).

\section{Cryptocurrency and Digital Development}

Babkin et al. (2018) stated that the main idea of cryptocurrencies is to eliminate the middleman, the third party coordinating two parties during the exchange process. Cryptocurrency is a peer-to-peer, electronic cash exchange system. The usual way to buy an item is by paying cash directly to the seller, but buying and paying online will transfer the money through the Internet to settle the payment, and money won't be delivered directly to the seller, it must be transferred via a third party as an exchange of money, and this third party must have the authority to access the bank account and use the money (Baldimtsi et al., 2017).

Gurrib et al. (2019) stated that digital development is so fast that it creates huge social disparities between countries, where developed countries may feel quite good with this rapid change, while poor countries and developing countries are facing some issues and lose the opportunity to be part of this development. Poor people have to remain within traditional systems which deprive them of many opportunities and incur huge losses that they cannot bear.

\section{Bitcoin Investment Incentives}

According to (Duque, 2020), there are five key reasons to invest in bitcoin now, in 2021. Those reasons were discussed in a published article after a historical analysis of bitcoin prices development during the past four years. These reasons have been justified and proven due to bitcoin's surrounding circumstances.

First of all, the adoption of bitcoin is becoming a fact with no boundaries, and the rate of this adoption is very much accelerating, while bitcoin holders are becoming richer than expected. A lot of bitcoin holders show a spectacular trust in guardianships and they are very 
satisfied and happy to keep their bitcoins in custodians, such as Coinbase, Square's Cash App and others (Baumöhl, 2019).

\section{Bitcoin During Pandemics}

Normal situations usually have no great effects or dramatic changes, except some innovative and creative insights that might make a difference in the future. On the other hand, abnormal situations may have the opposite effect, they are playing the role of a stimulus to desired change (Babkin et al., 2017).

Coronavirus has triggered a lot of stimuli. It has changed the face of the world and introduced many things that were not present or widely spread earlier. This virus has made a big change in the lives of millions of people. It affected people's health, social and cultural life, economical condition and even political situation. Finally, this virus has become people's main concern for many days.

\section{Bitcoin Perception and the Chance for Adoption}

Bitcoin seems to be one of the biggest challenges confronting the traditional monetary system since it was created. The great rise in the price of bitcoin was shocking to the economic world, there have been several sharp rises and declines later, but the continued rise in the price created a great desire among the general population to acquire this currency. The large emerging demand for this currency contributed to further rises in price. In addition to that, several large companies have announced they now accept this currency as a means of payment for their products. In the past century, no one heard of digital currency as such, and in the present day we can say that digital currency has become a reality that depends on the confidence of people while it grows and spreads (Hashemi et al., 2019).

Since Tesla Company was one of the first initiators in using bitcoins, such a courageous decision was based on long-term insights that comply with their overall strategy and vision.

eBay, Amazon, and many other companies offer their products and commodities in Bitcoin, and other, similar currencies. Alfa and Touch, two Lebanese mobile network, sell two products in BTC "Alfa PIN Lebanon" and "Touch PIN Lebanon", by which they show a symbolic activity and limited involvement in digital development through trading and exchanging of cryptocurrencies (Adhami et al., 2018).

Alonso-Monsalve et al. (2020) stated that bitcoin demand is a normal reaction to the surrounding circumstances, and even more, it is the normal result from the exceptional situations such as the coronavirus pandemic. People are trying to escape from the traditional modes of doing things and exercise new technological ways.

Bartos (2015) stated that expert opinions are responsible for changing the perception of people on various vital subjects, therefore, experts must be convinced of the offered change in the first place. Accepting a new monetary system is a great challenge for people. Bitcoin has to have a supportive marketing campaign that would demonstrate the importance of it and highlights all the advantages.

The undergoing bitcoin revolution should be accompanied by a determined strategy that is based on the principles of transparency, security and instant servicing. Bitcoin guardianships and supporting companies should do their best to convince other specialists 


\section{THE EFFECT OF BITCOIN ON THE GLOBAL ECONOMY}

and everyone that bitcoin is a good investment. On the other hand, to be credible they also have to be frank and be telling people that volatility and risk are the possible disadvantages (Bech \& Garratt, 2017).

\section{Data Analysis Techniques and Procedures}

In this study data collection is followed by the exploratory research design. Selection of an analysis approach depends on the type of theory being investigated. In this research, the best-suited is the inductive approach, and it is important to say that this kind of approach is a must when the researcher has sufficient knowledge on the subject being studied. The inductive approach aims to find and recognize the meanings in the collected data, to explore and understand the social context and the participants' perceptions.

The collected data have been coded to be analyzed using the IBM SPSS analysis software tool.

It is important to mention here that adapting the questions is an obligatory element which ensures the reliability of the results.

As the most appropriate sampling technique we have chosen the non-probability sampling technique.

The researcher considers himself to be self-involved in this field since he needed to judge the studied cases so he decided to use purposive sampling. This type of sampling requires the researcher to use his judgment to select cases that will best help him/her to answer the research question and meet the preset objectives.

The sample of the research includes experts (university instructors, CEOs, general managers, economists, financial experts, accounting experts) and also common people, either involved, or not involved with cryptocurrencies.

\section{Findings (Descriptive Statistics)}

In this research, the basic information was divided into two main types - primary and secondary data. During the research period, interviews have been conducted and questionnaires have been distributed. Although both of these methods were electronic, there was also some direct contact with some interviewees and some of the surveyed people too.

The paradoxical discovery is that most of the surveyed have more than just basic information about digital/crypto currencies. This makes you think that technology is indeed becoming more and more available for everyone.

When someone is going to sign up to whatever website and creates an account, these sites ask about some mandatory basic info to let them sign up. Some people have concerns about these requirements and sometimes they give fake information. But when it comes to online shopping, people should provide real information. Some other websites or apps have a verification process to assure that the signed-up party is not a robot or a fake account. Such verifications can be realized via phone numbers, Facebook or Outlook accounts, and other, similar methods. 
Table 1 - Confidential Information (data on surveyed persons) (made by the authors)

\begin{tabular}{|l|c|c|c|c|c|}
\hline \multicolumn{2}{|c|}{} & Frequency & Percent & Valid Percent & $\begin{array}{c}\text { Cumulative } \\
\text { Percent }\end{array}$ \\
\hline Valid & 1 & 43 & 38.4 & 38.4 & 38.4 \\
\cline { 2 - 6 } & 2 & 22 & 19.6 & 19.6 & 58.0 \\
\cline { 2 - 6 } & 3 & 23 & 20.5 & 20.5 & 78.6 \\
\cline { 2 - 6 } & 4 & 17 & 15.2 & 15.2 & 93.8 \\
\cline { 2 - 6 } & 5 & 7 & 6.3 & 6.3 & 100.0 \\
\cline { 2 - 6 } & Total & 112 & 100.0 & 100.0 & \\
\hline
\end{tabular}

Confidential info is much more sensitive than basic info, therefore, we can find that the majority of people are not comfortable with giving such kind of info without being sure that this info will not be stolen later.

Table 2 - Knowledge About Cryptocurrency

(made by the authors)

\begin{tabular}{|l|l|c|c|c|c|}
\hline \multicolumn{2}{|l|}{} & Frequency & Percent & $\begin{array}{c}\text { Valid } \\
\text { Percent }\end{array}$ & $\begin{array}{c}\text { Cumulative } \\
\text { Percent }\end{array}$ \\
\hline Valid & $\begin{array}{l}\text { I heard about it, but I } \\
\text { know nothing } \\
\text { concerning it }\end{array}$ & 33 & 29.5 & 29.5 & 29.5 \\
\cline { 2 - 5 } & $\begin{array}{l}\text { I know a little bit about } \\
\text { it }\end{array}$ & 24 & 21.4 & 21.4 & 50.9 \\
\cline { 2 - 6 } & I Know about it & 44 & 39.3 & 39.3 & 90.2 \\
\cline { 2 - 6 } & I've never heard about it & 11 & 9.8 & 9.8 & 100.0 \\
\cline { 2 - 6 } & Total & 112 & 100.0 & 100.0 & \\
\hline
\end{tabular}

Table 3 - Would like to know more about cryptocurrency ? (answers) (made by the authors)

\begin{tabular}{|c|c|c|c|c|c|}
\hline \multicolumn{2}{|c|}{} & Frequency & Percent & $\begin{array}{c}\text { Valid } \\
\text { Percent }\end{array}$ & $\begin{array}{c}\text { Cumulative } \\
\text { Percent }\end{array}$ \\
\hline \multirow{3}{*}{ Valid } & 1 & 4 & 3.6 & 3.6 & 3.6 \\
\cline { 2 - 6 } & 2 & 3 & 2.7 & 2.7 & 6.3 \\
\cline { 2 - 6 } & 3 & 19 & 17.0 & 17.0 & 23.2 \\
\cline { 2 - 6 } & 4 & 33 & 29.5 & 29.5 & 52.7 \\
\cline { 2 - 6 } & 5 & 53 & 47.3 & 47.3 & 100.0 \\
\cline { 2 - 6 } & Total & 112 & 100.0 & 100.0 & \\
\hline
\end{tabular}


We can observe that the majority of surveyed would want to know more about cryptocurrencies without any hesitation (Tab. 1,2,3 and 4).

Table 4 - Results of the survey

(made by the authors)

\begin{tabular}{|c|c|c|c|c|c|}
\hline & & Frequency & Percent & Valid Percent & $\begin{array}{c}\text { Cumulative } \\
\text { Percent }\end{array}$ \\
\hline \multicolumn{6}{|c|}{ Mining Concept } \\
\hline \multirow[t]{3}{*}{ Valid } & No & 68 & 60.7 & 60.7 & 60.7 \\
\hline & Yes & 44 & 39.3 & 39.3 & 100.0 \\
\hline & Total & 112 & 100.0 & 100.0 & \\
\hline \multicolumn{6}{|c|}{ Bitcoin Value } \\
\hline \multirow[t]{3}{*}{ Valid } & No & 55 & 49.1 & 49.1 & 49.1 \\
\hline & Yes & 57 & 50.9 & 50.9 & 50.90 \\
\hline & Total & 112 & 100.0 & 100.0 & \\
\hline \multicolumn{6}{|c|}{ Cryptocurrency Ownership } \\
\hline \multirow[t]{5}{*}{ Valid } & Bitcoin & 13 & 11.6 & 11.6 & 11.6 \\
\hline & $\begin{array}{l}\text { Bitcoin } \\
\text { and other }\end{array}$ & 3 & 2.7 & 2.7 & 14.3 \\
\hline & None & 62 & 55.4 & 55.4 & 69.6 \\
\hline & Others & 34 & 30.4 & 30.4 & 100.0 \\
\hline & Total & 112 & 100.0 & 100.0 & \\
\hline
\end{tabular}

Almost half of the surveyed people already knew the value of bitcoin at the moment they were surveyed.

\section{Analysis}

Most of the answers are related to the benefits of the cryptocurrency concept. As we can see, most of the participants have positive attitudes towards this notion. Decentralization, in its general sense, usually has a positive effect on people's opinions, therefore, the majority of answers were demonstrating a significant level of support for the concept.

Despite all the types of the related risks, majority of our respondents still think that this kind of change has many benefits but it needs to be regulated and legalized.

Trust is the most basic factor that affects the perception, when people have no idea where their assets are. Thus, they may be excused about their concerns. At this, the role of guardianship authority is to explain the related security principles to those people.

The key target of any kind of investment is profit. When people see and hear that bitcoin started with $\$ 0.00$ and today is worth tens of thousands, they are often heavily seduced. Many people dream of becoming a millionaire overnight, effortlessly, or just with a small investment made. This is actually a reality for some bitcoin owners who indeed have become rich overnight, in every sense of the word. 
The lack of information has the opposite effect in this context - some people may distrust guardianship, despite all the profit temptations. They can be still attracted, but without exposing them to theft or danger of any other kind.

People tend to appreciate freedom in every aspects of their life. In the banking system, the middle man (intermediary) is one essential element in any type of banking transactions. At the same time, under the decentralization system this third party does not exist as such due to direct relation between two parties. People like this, but at the same time they tend to be conservative when it comes to regulation and legislation.

Transition is one of the important steps towards the digital world, but it certainly needs some time to settle and become solid.

\section{Conclusion}

In the context of ongoing and rapid digital development, this research has been aimed to understand the differences between the actual monetary system and the expected digital one. In developing countries, the economies are often unable to help themselves institutionally. It is worth mentioning here that talking about the economies of poor countries is crucial because these countries might still have some successful institutions that need to be globalized.

Under the conditions of ongoing globalization, all countries need to become part of the common economic world, otherwise, they will remain underdeveloped and confined regionally.

Our study has been conducted to discover the real perceptions among the experts and general population towards the concept of cryptocurrency and bitcoin. Taking into account all the ups and downs of the cryptocurrencies, bitcoin especially, it is still obvious that the overall perception is very much positive. At the same time, the concept of cryptocurrency still needs clearer explanations, among the general population especially. The mysterious prospects accompanying bitcoin make it difficult to convince people to change their opinion and attitude.

\section{Limitations}

The ongoing coronavirus pandemic has been playing a highly negative role in the all sectors of human activities, and research activities have been obviously also affected by this pandemic. Qualitative research, in our base, has been based on people's opinions and points of view, and to investigate those opinions and points of view we had to conduct interviews and distribute questionnaires. Ideally, such interviews should be face-to-face, but due to the pandemic restrictions they were conducted electronically, some of them were organized during a phone call to elaborate some ideas and to discuss insights.

Since cryptocurrency is not a local project but rather a global one, some of the interviews were done with stakeholders abroad, and this fact clearly has its impact on the final results. Moreover, experts' opinions about the concept of digital/cryptocurrencies have become a significant part of our research, some of those opinions were actually extracted from the articles published on the Internet. 


\section{THE EFFECT OF BITCOIN ON THE GLOBAL ECONOMY}

\section{Recommendations}

From the outcomes we have obtained and presented above, we may recommend conducting more than one research concerning cryptocurrencies, and especially about the laws and regulations in force. Serious consulting with experts and legislators is required to define the mechanisms and actions that would eventually enhance people's confidence in these currencies.

In addition, it is recommended to clarify the extent of security and safety of assets and information related to their owners. This would also strengthen the confidence of general population in bitcoin and other cryptocurrencies.

The people who are directly and currently involved in the circulation of digital currencies represent the most prominent group of potential marketers. Therefore, guardianship authorities should keep them feel grateful and comfortable in order not to lose them.

\section{References}

Adhami, S., Giudici, G., \& Martinazzi, S. (2018). Why Do Businesses Go Crypto? An Empirical Analysis of Initial Coin Offerings. Journal of Economics and Business, 100: 64-75.

Alonso-Monsalve, S., Suárez-Cetrulo, A. L., Cervantes, A., \& Quintana, D. (2020). Convolution on Neural Networks for High-Frequency Trend Prediction of Cryptocurrency Exchange Rates using Technical indicators. Expert Systems with Applications, 149: 113250.

Babkin, A. V., Burkaltseva, D., Pshenichnikov, W., \& Tyulin, A. (2017). Cryptocurrency and Blockchain-Technology in Digital Economy: Development Genesis. St. Petersburg State Polytechnical University Journal. Economics, 67(5): 9-22.

Baldimtsi, F., Kiayias, A., \& Samari, K. (2017). Watermarking Public-Key Cryptographic Functionalities and Implementations. In: Nguyen, P. Q., \& Zhou, J. (Eds.). Information Security: 173-191.

Baldwin, J. (2018). In Digital We Trust: Bitcoin Discourse, Digital Currencies, and Decentralized Network Fetishism. Palgrave Communications, 4(1): 1-10.

Bartos, J. (2015). Does Bitcoin follow the hypothesis of the efficient market? International Journal of Economic Sciences, 4(2): 10-23.

Baumöhl, E. (2019). Are Cryptocurrencies Connected to Forex? A Quantile CrossSpectral Approach. Finance Research Letters, 29: 363-372.

Bech, M. L., \& Garratt, R. (2017). Central Bank Cryptocurrencies. BIS Quarterly Review, September. 
Duque, J. J. (2020). State Involvement in Cryptocurrencies. A Potential World Money? The Japanese Political Economy, 46(1): 65-82.

Gurrib, I., Kweh, Q. L., Nourani, M., \& Ting, I. W. K. (2019). Are Cryptocurrencies Affected by Their Asset Class Movements or News Announcements? Malaysian Journal of Economic Studies, 56(2): 201-225.

Hashemi J., M., Nishikawa, Y., \& Dandapani, K. (2019). Cryptocurrency, a Successful Application of Blockchain Technology. Managerial Finance, 46(6): 715-733.

Larios-Hernández, G. J. (2017). Blockchain Entrepreneurship Opportunity in the Practices of The Unbanked. Business Horizons, 60(6): 865-874.

Maurer, B., Nelms, T. C., \& Swartz, L. (2013). When Perhaps the Real Problem is Money Itself! The Practical Materiality of Bitcoin. Social Semiotics, 23(2): 261-277.

Mendoza-Tello, J. C., Mora, H., Pujol-López, F. A., \& Lytras, M. D. (2018). Social Commerce as a Driver to Enhance Trust and Intention to Use Cryptocurrencies for Electronic Payments. IEEE Access, 6: 50737-50751.

Paper submitted

Paper accepted for publishing

Paper published online
24 July 2021

17 September 2021

30 September 2021 